\title{
Survey on the Public Speaking ability of Engineering Graduates
}

\author{
Chennakampalli Chethan Reddy \\ Department of Computer Science \& \\ Engineering \\ Saveetha Engineering College, \\ Chennai.
}

\author{
Sushiridha. A \\ Department of Computer Science \& \\ Engineering \\ Saveetha Engineering College, \\ Chennai
}

\author{
Dr. M. Selvi \\ Department of Electronics \& \\ Communication Engineering \\ Saveetha Engineering College, \\ Chennai.
}

\begin{abstract}
Public speaking skills are extremely essential for maximum professionals today. The majority of their appraisals and assessments depend on this skill, thus it is important that the students are prepared before taking a stride from academic life to professional life. The purpose of this study is to analyse the reasons behind the anxiety levels of 107 undergraduate students and recommend strategies to overcome this notion. The findings have helped many of the students to improve their abilities. Around $75 \%$ of the participants openly admitted their fear of public speaking and around $45 \%$ of the participants have never really given a speech. This $45 \%$ of students are worrying about something which they have never really experienced. Researches also showed that exposure to virtual environments makes it simpler for students to express themselves and boost confidence.
\end{abstract}

Keywords--- Public speaking, anxiety, fear, confidence, Gloss phobia.

\section{INTRODUCTION}

When it comes to speaking in public, everyone has their own style. Confident, jittery, tense, shy, monotonous, anxious, etc. Despite being able to communicate elegantly on a daily basis, most people face fear and resistance to speak in front of a huge audience. And the reasons for this are plenty. Public speaking is a skill, which can be attained from good training. No one is born as a public speaker; they learn it. After all, even the Father of our nation has had this problem.

Mahatma Gandhi has suffered from frequent panic attacks. On one of his early public speeches in London, while addressing the vegetarian community, he couldn't speak more than two sentences and gave his papers for someone else to read. And during his first case as a lawyer, he panicked in front of the judge and left the courtroom.

But Mahatma Gandhi overrode all his fears and nervousness to become one of the greatest leaders and speakers the world has ever seen. He was able to convince the whole country. That is the power of public speaking. If you learn this, it can make you outstanding, and barely by not having the skill alone can restrain you from reaching your highest potential.
People who converse easily in regular conversations also have a problem in speaking their thoughts when they become the center of attraction and focus. It is important for such people to understand that they are not the only ones who face these emotions; as a matter of fact, almost every speaker feels the same. There are more nervous speakers in the world than those who are not.

Public speaking is a combination of various distinct skills like communication skills, presentation skills, time management, language skills, etc. Professionals these days are expected to be updated with their communication and presentation skills. Students must understand that public speaking is just a form of human communication added with special effects.

Traditionally public speaking was considered to be a part of the "Art of persuasion". Public speaking is an art that can entertain, inform, and persuade people. Public speaking was developed in Rome and Greece. In those days, they used this for influencing development and evolution. Today, technology continues to modernize this art into live video conferencing, multimedia presentations, and other non-traditional ways.

Anxiety is defined as a feeling of worry, nervousness, or unease about something with an uncertain outcome. According to Kirkwood and Melton (2002), anxiety disorders are among the most common mental disorders encountered by public speakers. People with anxiety tend to avoid all public situations even if it's forced on them, they suffer intense distress and difficulty. When such people speak, it's natural that the public might lose interest shortly as the speaker fails to render confident gestures. All these are hurdles in reaching one's personal and professional goals. Thus, it's important for any person to improve their public speaking skills.

Students should be given opportunities to perform in front of their peers and an unfamiliar audience too. This exercise would improve the learner's confidence and reduce anxiety levels. Every student must get a chance to speak up and realize that their opinions matter as well. This has to be practiced in schools and homes. At home, whenever the younger ones try to make a conversation with you, make 
time to listen to them. It would help them to be more expressive.

The purpose of this study is to help students and professionals improve their public speaking skills by analysing the problems they face while being in the spotlight. The study presents the causes of the hurdles in public speaking and solutions to deal with them. It includes descriptive details of the results and schools of surveys.

\section{THE ART OF PUBLIC SPEAKING}

So, what is public speaking? It is a presentation that's given live in front of an audience. The objectives of the speech might be to educate, entertain, or influence the listeners. Lately, speakers use various visual aids such as PowerPoint presentations and demonstrations to make the speech more interesting and engaging. There are so many factors that influence the effectiveness of a speech.

It isn't surprising that public speaking has prevailed for a long period. The trace of the origin of public speaking goes back to ancient Rome and Greece about 2000 years ago. The ancient Greeks mostly used public speaking for praising and persuading others. At this point, they had the right to oppose or support the law, which resulted in the need for social orators. The need for public speaking in Greece was mostly political but then Rome came to power. Public speaking was used during various sessions of the governing body- the Roman Senate. The Greek called public speaking as rhetoric at that time. The Romans adopted public speaking rhetorically. As a matter of fact, most of the public speech trainers were Greek back then and even today we follow a few of those methods.

Fast-forwarding to modern times, the Latin style of public speaking was popular in the U.S and Europe until the mid-20th century. After world war 2, a less formal and more conversational form of speaking became popular. Then electronic tools were used to enhance public speaking. Towards the end of the 20th-century software tools like PowerPoint were put to use. Although we have a less formal way of public speaking today, the anxiety it gives has never reduced.

\section{IMPORTANCE OF PUBLIC SPEAKING}

There are not many people who appreciate public speaking. They are either not interested or confess that they are scared. Communication is the backbone of our society. It allows us to form connections, influence decisions, and motivate changes. Public speaking is one of the most important and most dreaded forms of communication. Glossophobia or speech anxiety is one of the most common fears.

Students have a tendency to sit in the back of the class and dodge all the questions they are asked in their classes but in their career, it is one of the most vital skills. Public speaking skills can impact your everyday conversation both professionally and personally in a promising way. This skill can help you reach a great level in your career and personal relationships as well.

Oral communication skills were the number one skill that college graduates found useful in the business world, according to a study by sociologist Andrew Zekeri (Zekeri, 2004). This alone explains why it is worth learning this skill.

\section{BENIFITS OF PUBLIC SPEAKING}

Besides assisting students and professionals to deliver effective speeches, public speaking also delivers additional benefits-

- developing critical thinking skills

- fine-tuning of verbal and non-verbal skills

- overcoming stage fear

- Improves confidence

- Better research skills

- Stronger deductive skills

- Improve upon your knowledge

- ability to demonstrate your knowledge

- Ability to advocate for causes and more.

Public speaking is essential for business management since they have to convey their messages to potential customers and market their business products.

We live in a materialistic society and our self-esteem and self-worth are attained by our perception of what others think about us. By speaking in public, you automatically become more confident in communicating with people thereby increasing your skill at perceiving people's responses to your words. This boosts you up and increases self-confidence.

This skill can also reduce those awkward conversations which you wish you never had. Everyone has had a moment where we don't open up or stumble and utter something senseless. As you acquire the skill of speaking, you are less likely to be stuck in an awkward conversation. You would be comfortable and confident in having conversations. Public speaking will always remain as one of the best ways to get your message across a large audience and express yourselves.

At some point in your life, this skill will always come in handy. It will allow you to make a difference in your life, business, career, and community. This skill will improve your communication skills, leadership skills, confidence, and ability to understand and read people. This skill helps you prepare for the worse.

It never harms anyone to learn something that is hugely beneficial.

\section{HOW TO GET BETTER AT PUBLIC SPEAKING?}

So now that you know the benefits of public speaking you might be a little more interested in learning it. But you dread public speaking? Join the club. It is what most people fear along with the fear of death and spiders, so you are not alone. While some people may have more natural speaking ability than others, or a more pleasing voice, or are more charismatic anyone who can speak can learn to be a better 
public speaker than they are right now. It just takes some know-how and effort.

\section{A. Frame the skeleton}

Before you start writing down the script or begin with the presentation you must get your purpose clear. Get your goals straight, like:

1) Who is your audience?

2) What are you trying to accomplish?

3) Are you there to inform? Inspire? or persuade?

4) What impact do you want to leave on your audience?

Knowing your ultimate end will help you stay focused through the preparation process and presentation.

\section{B. Prepare}

Now prepare on a roadmap of what you are going to say. Write down what you want to tell in a well-organized way so that you don't mess up with the order. Even if you have got a great voice or charms in your voice, your speech won't go well if your material isn't good. Surveying 107 students we got to know around $43 \%$ of the students are bored by unprepared speakers. Hence, make sure you prepare well. Here are a few tips for you to prepare well:

\section{Simplify}

you might be a scholar in the topic you are talking about. So, don't just bombard people with a lot of new information, this will make your audience suffocate. Keep your presentation as simple as possible which will help everyone in the room to understand. Being too verbose also bores the audience (Based on the survey-14\% of the students feel this way). Great public speakers are those who reach each and everyone in their audience. As Albert Einstein said, "If you can't explain it to a six-year-old, you don't understand it yourself".

\section{Short}

We have all been through long and exhausting presentations at the end of which we hardly remembered anything. So, it's important that you keep all the information tight-packed.

\section{E. Overuse of electronics}

Crammed up PowerPoint presentations are a distraction. If you need pictures, graphs, etc. to support your speech, always make them elegant. Never fill your PowerPoint presentations with information. Having too many slides with so many information also distracts around $30.8 \%$ of the students. Your goal is to hold the attention of the room and never lose it.

\section{F. Personalize}

It's always easier to remember stories than facts and figures. So never forget to add personal stories to your speeches. Everyone has stories to tell, so choose the right one to speak that is related to the topic of your speech.
Telling a story will also help you, as you will remember it better on the stage.

\section{$G$. Connect with the audience}

Never go on the stage just to prove that you are smart. You are on the podium for a reason. There is already a gap between the person on the stage and the audience. Your job is to bring them closer, not widen it by proving intellect. Make your speech self-effacing, real and humorous. This way the audience will pay more attention to you.

\section{H. Give something}

Most of the speakers today expect something in return. For example, politicians speak because they need our votes, social media influencers speak to increase their followers, and some of them even for money. Great speakers are those who really want to give something to the audience and not just take. It's fine to want something in return but it's not okay when your motive is purely to grab.

\section{Practice}

Practice makes a man perfect, so in addition to writing down your speech, it's also important that you practice that and form an idea of the way you are going to present it.

\section{J. Rehearse}

Present your speech to your teachers or friends. This allows you to have a clear road map of what you are going to say and the way you are going to speak.

\section{K. Variation}

Sameness is the enemy of the speaking. Don't let your audience tune out by using the same vocal rhythm, pitch, tone, and gesture. You need to change it; keep enough variations in your delivery so that your audience never gets bored. Make sure that you practice your variants too.

\section{Movement}

It is said that about $90 \%$ of the communication is done non-verbal. Your audience will read your facial expression, the tone of your voice, the way you move your hands, and how you stand and move. A warm, easy smile and confident body tell the audience that you are comfortable. This makes both parties fulfilled.

\section{Watch yourself}

Video record yourself speaking and correct your mistakes. When you see yourself, it makes it easier to grasp your mistakes. See to it that you don't wander a lot on stage, over-gesture, slouch, grim facial expressions and repeat speech patterns.

\section{N. Feedback}

Get feedback from your audience and work on them. Never neglect feedback. Always go to your best critic for the response. 


\section{O. Time limits}

Never make your speech longer than 20 minutes. In a survey, $27 \%$ of the students have reported that speeches longer than 20 minutes are boring. So, work within time.

\section{P. Check position}

Make sure that microphones are in positions and are in good condition. If you're taking part in a competition, remember the people before and after you so that you don't miss your slot. This will reduce your tension on stage.

\section{Q. On stage}

Now that you have written a beautiful speech, feel more confident about what you are going to say. Always show up to the venue a few minutes before so that you can relax.

\section{$R$. Overcoming stage fright}

Take a deep breath before you go on the stage and visualize your success. Visualizing your success always helps in boosting your confidence. If you have some friends in the audience, focus on them. This way you feel less fearful. Don't fear the monetary silence, it isn't wrong to take a few small pauses. Also, it is most nervous during the minute before you enter the stage. You must keep yourself occupied at that time by visualizing positive outcomes.

\section{S. Make yourself comfortable on stage}

Focus on a spot at the end of the room, just above the heads of the people in the last row. This makes everyone assume that you are looking at them but you are looking at the wall.

\section{T. Don't change anything in the last minute}

Just go with whatever you have prepared.

\section{U. Don't tell anything you don't believe in}

Speak only about the things you are passionate about. There is no substitute for authentic passion.

\section{$V$. Everyone has a different kind of energy}

Make good use of that energy on stage. Use your anxiety and fear as energy to engage with people. Make jokes about your fear on stage that connects greatly with the audience.

[1] Never mind if your speech doesn't move as planned or you miss a few points; everyone does. The difference is in how you manage it. Always have some questions prepared. You can ask them to the audience whenever your anxiety is at a peak. This way you will have time to relax and think about what you are going to say next.

[2] Tell yourself that the presentation is not about you; it's about helping your audience. Convey every ounce of knowledge you have on the topic, just as you prepared.

[3] Reading this alone will not help. You need to practice these techniques. It will enable you to overcome your fears and anxiety faster.
[4] It's exciting that $90 \%$ of the students realize practicing public speaking will help them overcome their fear and yes, their understanding is $100 \%$ true

\section{OBSERVATION}

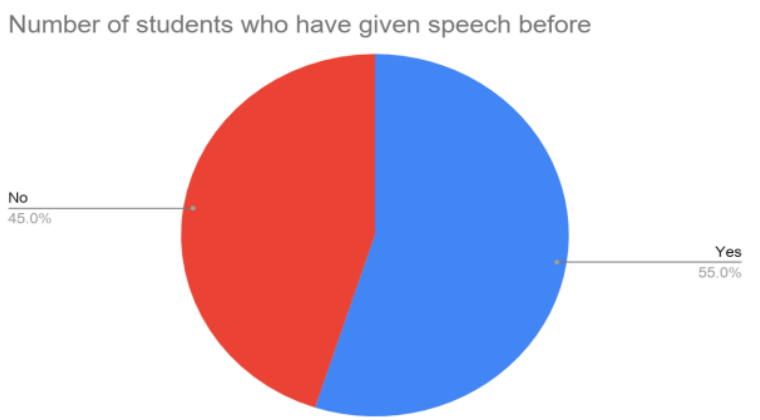

From the above chart we can understand that many students are just afraid of public speaking even before they have tried it. Every student should be given a chance to speak up. College and schools should make sure, that each student at least speaks in public one time.

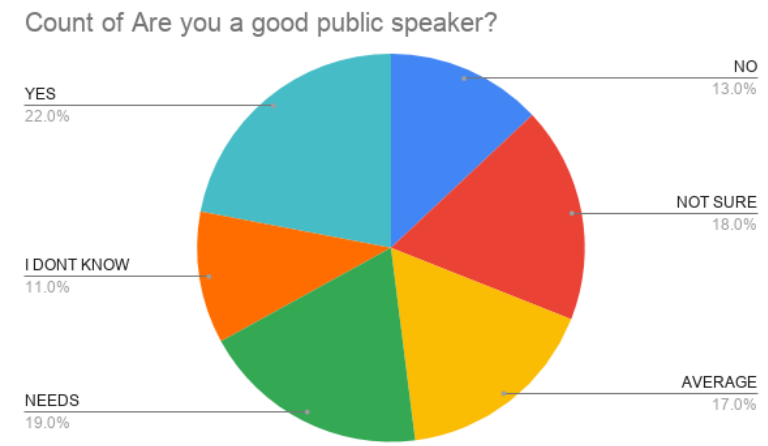

From the above graph we can conclude that only $22 \%$ of people are good at public speaking

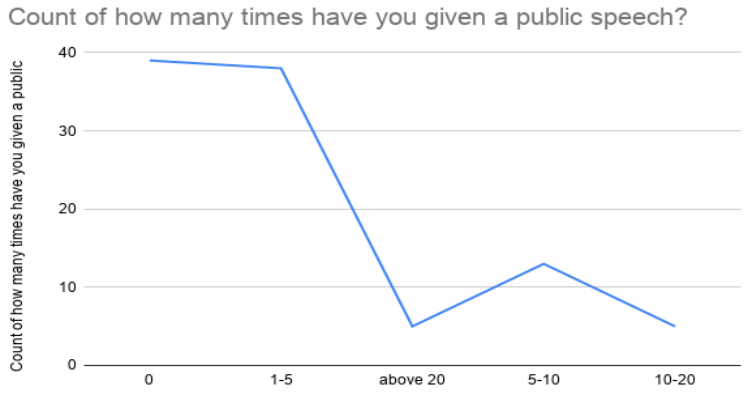

There are many students who still haven't even given or attempted to give a public speech 
Do students think public speaking is a learnable thing?

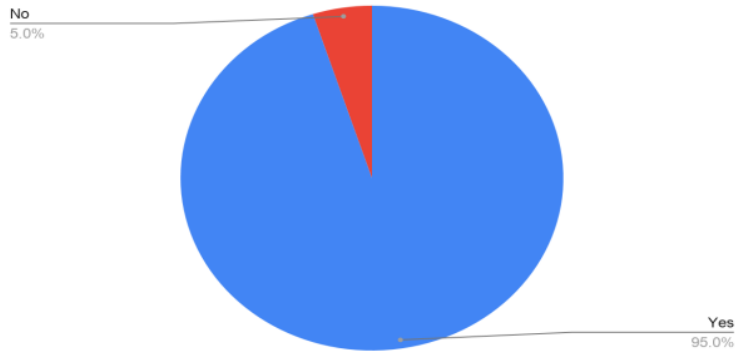

Students believe that they can learn this skill, so educational institutes should give them an opportunity to learn it.

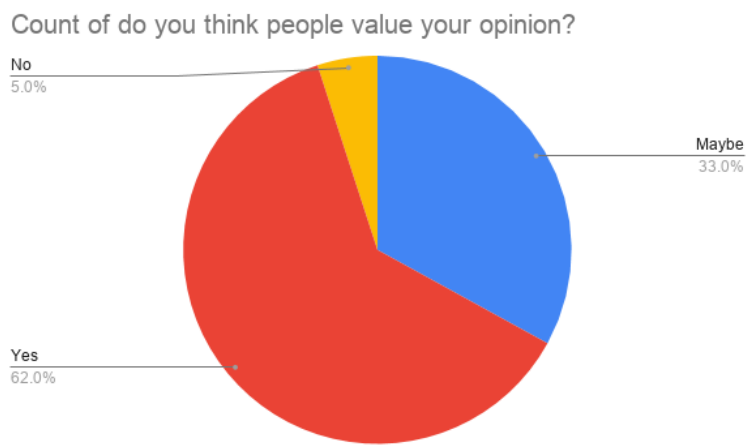

Self-doubt consumes many of us today. Students of this generation are more lost than ever. So, neglecting any of their opinions ends bad. Hear people (friends), it will help both of you.

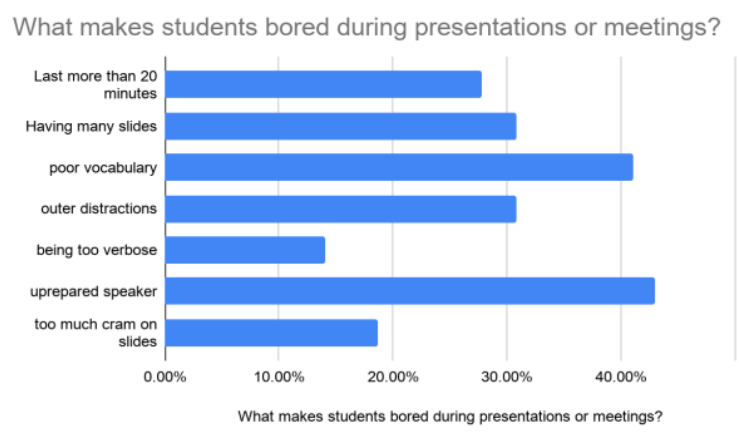

This graph shows where students need to concentrate when they are giving a speech. So that we don't make the same mistake and learn from it.

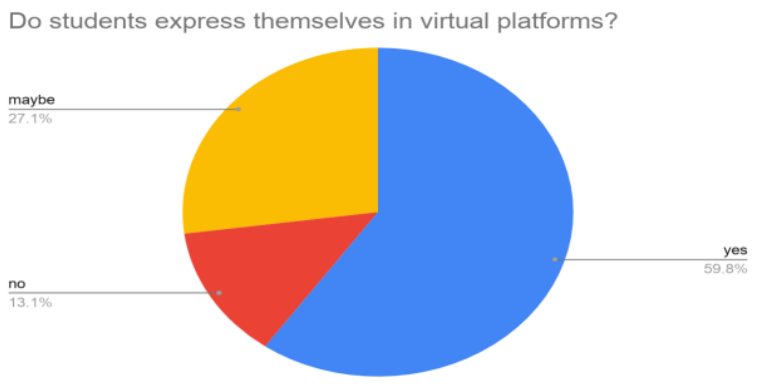

Students exposed to virtual environments tend to be better at expressing themselves well. Social media has its positive sides too.

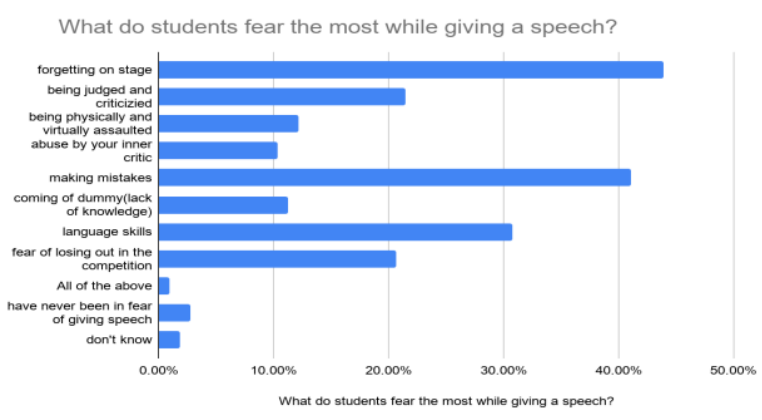

All these things that students fear of while giving a speech can easily be solved by proper preparation and training

\section{CONCLUSION}

The research shows that the above tips helped many of the students to overcome their fear of public speaking and we also hope that it helps you. Educational institutes should have a separate club for public speaking to ensure that their young buds are given proper training to aid them in this skill. Public speaking might come naturally for few but others might need a push. Educational institutes should acknowledge this skill with the significance that it deserves and provide proper guidance to their students. Joining an active public speaking forum would also benefit the students. Once they start considering themselves comfortable in an unfamiliar environment while speaking, their pressure levels would automatically go down and make them feel at ease. Hence, students must join hands with their educational institutions to organize public speaking forums to seek knowledge and grow.

\section{REFERENCES}

[1] https://www.isbtweb.org/fileadmin/user_upload/successfulpublic-speaking.pdf

[2] https://en.wikipedia.org/wiki/Public_speaking

[3] https://business.tutsplus.com/tutorials/what-is-public-speaking-cms-31255

[4] https://www.forbes.com/sites/susantardanico/2012/05/29/want-tobe-a-better-public-speaker-do-what-the-pros-do/\#1b9967611e17

[5] ] Book :The art of Public speaking -By Dale Carnegie https://books.google.co.in/books/about/The Art_of_Public Speak ing.html?id=rJihlQEACAAJ\&redir_esc $=y$

[6] https://ijlcnet.com/journals/ijlc/Vol_2_No_4_December_2014/4.p

[7] https://openprairie.sdstate.edu/cgi/viewcontent.cgi?article $=1059 \&$ context=jur

[8] ]https://pdfs.semanticscholar.org/cad3/2ccab4970690785a84385f af33caaa5d6535.pdf

[9] ]http://www.ijhssnet.com/journals/Vol._1_No._7_[Special_Issue June_2011]/2.pdf

[10] Course:https://www.coursera.org/specializations/publicspeaking?skipBrowseRedirect=true 